\title{
Early childhood traffic-related air pollution, boys, parental allergy, stressful family events, and risk of allergic rhinitis at 4 years of age in Shenyang, China: a case-control study
}

\author{
Shuai Hao ${ }^{1}$, Fang Yuan ${ }^{1}$, Pai Pang ${ }^{1}$, Bo Yang ${ }^{1}$, Xuejun Jiang ${ }^{1}$, and Aihui Yan ${ }^{1}$ \\ ${ }^{1}$ China Medical University First Hospital
}

July 9, 2020

\begin{abstract}
Abstract: Purpose: We aimed to evaluate whether early TRAP exposure is associated with the development of AR during preschool years, stratified by sex, parental allergy, or stressful family events. Methods: A nested case-control study including 398 was conducted in Shenyang. TRAP exposure in early childhood was estimated by nitrogen oxides (NOx) air dispersion modeling. We used multinomial logistic regression models to assess the association between early TRAP exposure and preschool children AR, stratified by potential confounders including sex, parental allergy, or stressful family events. Results: Life-time prevalence of AR in children aged 4 years $(6.4 \%)$ was associated with TRAP exposure during early children, with an increased odds ratio $(\mathrm{OR}$ ) [adjusted $\mathrm{OR}=2.18 ; 95 \%$ confidence interval $(\mathrm{CI}), 1.35$ to 3.52 ] for an interquartile range $(38 \mu \mathrm{g} / \mathrm{m} 3)$ increase in NOx levels. A relative risk for AR of of 1.88 (95\% CI, 1.26 to 2.81) with boys, of 1.91 (95\% CI, 1.28 to 2.85 ) among with eczema during the first year, of 2.94 (95\% CI, 1.77 to 4.87) with parents allergy, of 4.14 (95\% CI, 2.65 to 6.49) with stressful family events, was also observed. TRAP exposure was significantly associated with AR in preschool children who are boys (adjusted $\mathrm{OR}=2.13 ; 95 \% \mathrm{CI}, 1.31$ to 3.45 ), with parental having allergy (adjusted $\mathrm{OR}=2.06,95 \% \mathrm{CI}, 1.27$ to 3.36 ), and a history of stressful family events (adjusted $\mathrm{OR}=1.94,95 \% \mathrm{CI}, 1.18$ to 3.20 ). Conclusions: Early childhood TRAP exposure, boys, parental allergy, stressful family events may contribute to AR in children at 4 years of age.
\end{abstract}

\section{Hosted file}

Manuscript-resubmission.doc available at https://authorea.com/users/339352/articles/468331early-childhood-traffic-related-air-pollution-boys-parental-allergy-stressful-familyevents-and-risk-of-allergic-rhinitis-at-4-years-of-age-in-shenyang-china-a-casecontrol-study 